\title{
Cambridge Astronomy Without Sir Fred
}

Speculation about the motives for Sir Fred Hoyle's resignation from the Plumian chair of Astronomy and Experimental Philosophy at Cambridge, which was announced this week, is rife in astronomy circles in Britain.

The last straw which made Sir Fred tender his resignation according to reports from California where Sir Fred is this week attending a conference, was the decision of the university to appoint Professor Donald Lynden-Bell, currently of the Royal Greenwich Observatory and the University of Sussex to the chair of Astrophysics at Cambridge which falls vacant in October due to the retirement of Professor R. O. Redman, director of the Cambridge Observatories.

Professor Hoyle has made it clear that he has no personal objections to Professor Lynden-Bell but his protest is based on the fact that Lynden-Bell is a theoretical astronomer and Sir Fred thought that the university should have appointed an observational astronomer to the post.

Much confusion has been created by misinterpretations of the wording of the notice published last August in the Cambridge University Reporter asking for applications from suitable candidates for the chair of astronomy. At first glance it seems that the way in which the notice was written completely excludes theoretical astronomers from applying but a member of the board of electors to the chair of astrophysics pointed out this week that the notice was framed in such a way that this was not so. The announcement called for "an astrophysicist with an interest in fostering instrumental development". It seems that this wording was chosen after much discussion within the university and also after discussion with the Astronomy Policy and Grants Committee of the Science Research Council of which Sir Fred is the chairman.

The programme of research put forward by Professor Lynden-Bell fulfils these conditions, and according to one of the electors will ensure that the university and national policies on astronomy are dovetailed.

Electors of Cambridge University professorships hold office for four years and terms of office come to an end on the last day of September, four years after original appointment to the board. In the case of Professor Lynden-Bell's appointment the fact that two of the 1970-71 electors ended their terms of office in the time between the appearance of the notice of the vacancy and the appointment has led to charges that the appointment was at best mishandled and at worst, underhand. Electors are not changed once they have started on their deliberation to choose a new professor. The present board of electors consists of Professor F. G. Smith, Professor Sir Martin Ryle, Professor Sir Harrie Massie, Professor Sir Nevill Mott, Professor Sir William Hodge, Professor A. B. Pippard, Sir Richard Woolley and Professor Sir Fred Hoyle. This board differs from that of 1970-71 in that on October 1, 1971, Professor F. G. Smith replaced Professor P. Hall, and Professor A. B. Pippard replaced Professor Sir Bernard Lovell. The charges which have been laid against the university are that the 1970-71 board started on the task of appointing Professor Redman's successor but that contrary to the regulations Professor Lovell and Professor Hall were replaced on the board before the deliberations were completed and the task was finished by the 1971-72 board.

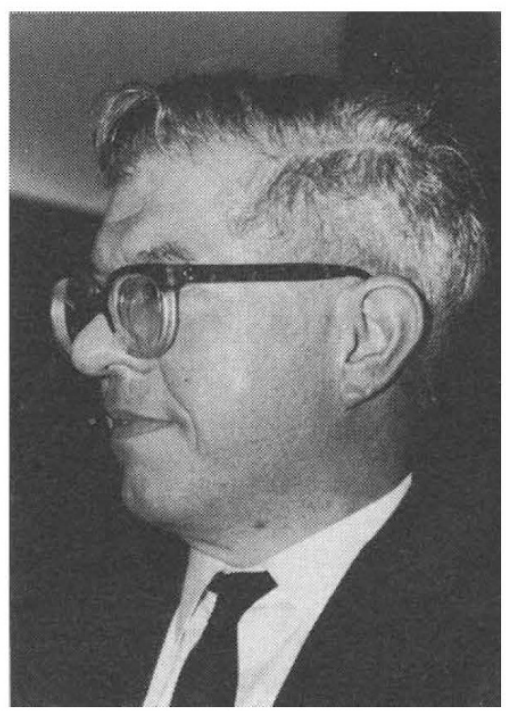

Sir Fred Hoyle

It seems, however, that the 1970-71 board never actually met to discuss the new appointment, although efforts were made to get them together before September 30, 1971. These did not turn out to be successful as it proved impossible to find a day when all members of the board were together in Britain at the same time. Thus the appointment was made completely by the 1971-72 board which held its first meeting in October, 1971.

Although the appointment of Professor Lynden-Bell might have been the last straw there is no doubt that Sir Fred was far from happy with other recent developments at Cambridge. In particular the decision taken by the uni- versity last November to merge the Institute of Theoretical Astronomy of which Sir Fred is the director, with the Cambridge Observatories in order to rationalize research in astronomy, has, it is rumoured, far from pleased Sir Fred Hoyle, signatory to the report which, even though he was a member, recommended the merger.

The Institute of Theoretical Astronomy was formed in 1966; it is widely believed that it was set up to keep Sir Fred Hoyle from joining the brain drain. The merger meant that Sir Fred would have lost his autonomy and it is now questionable whether the rich flow of summer visitors to the institute can continue in future years. The financing of the institute has been carried out on a three part basis with the Science Research Council providing 40 per cent of the cost which has amounted to $£ 250,000$ since 1966 . The Nuffield Foundation has provided a similar amount while the University of Cambridge has put in $£ 125,000$ since the inception of the institute. The financing of the merged departments is still uncertain; the SRC report that they have been considering it since early this year but no decision has yet been made. What is clear, however, is that the Nuffield Foundation will not be asked to provide finance for the merged body.

Sir Fred Hoyle's resignation will be felt in British astronomy circles and if he leaves the country for another post he will leave gaps to be filled on the Science Research Council, the Astronomy Space and Radio Board, the Astronomy Policy and Grants Committee, of which he is currently chairman, and the Anglo-Australian Telescope Board, although a spokesman for the SRC pointed out this week that there was no compunction on him to resign if he went to work outside Britain.

With Sir Fred Hoyle's resignation British astronomy will have lost the advantage it gained last summer when Professor Margaret Burbidge was wooed back from the United States to be director of the Royal Greenwich $\mathrm{Ob}$. servatory. The consensus among astronomers is that Sir Fred's resignation will not lead to a massive drain of astronomers from Britain and that astronomers will still be keen to work either at the enlarged centre at Cambridge or at the Astronomy Centre at the University of Sussex where Dr Martin Rees has recently been appointed as professor in succession to Professor W. H. McCrea. 